\title{
Silent talking: Indigenous media policy and the Productivity Commission
}

\author{
Michael Meadows
}

\section{Introduction}

Acknowledgment of the existence of the Indigenous media sector in Australia has been a long time coming. That Indigenous people might have concerns about the media content imposed upon them became an issue with federal government policymakers only 15 years ago. Perhaps it is not surprising then that the existencelet alone the significance - of the Indigenous media sector has remained at the periphery of the policymaking process for so long. But at the dawn of the new millennium, Indigenous media may have broken through the barrier of silence that has effectively kept the sector hidden from public view for so long.

The 1999 Productivity Commission inquiry into broadcasting has taken a bold step in its draft report. Not only does it acknowledge the existence of Indigenous media, but also it ascribes to it a significant place in the Australian broadcasting policy environment. Evidence of this is in four of the report's 28 recommendations which address issues within the Indigenous communications industry.

The Indigenous media sector is probably the only medium by which information can be effectively transmitted across the cultural and linguistic boundaries that have survived the impact of the past 212 years of white settlement. Audience surveys of Native broadcast media, particularly in the Canadian arctic, reveal that local media are the primary sources of information about Indigenous affairs for most Native people (Wilson 1993a; 1993b). Recent research suggests that is most certainly the case in many of the community radio and television stations across Australia. But it is also true that successful Indigenous community radio stations, like 4 AAA in Brisbane, and the commercial television station Imparja in central Australia, have audiences which are 70 percent non-Indigenous. This suggests the additional role Indigenous media plays as a 'cultural bridge' in informing non-Indigenous audiences of cultural issues and perspectives which otherwise remain largely silenced (Meadows and van Vuuren 1998). Like existing national and multicultural broadcasting services, government involvement in the Indigenous media sector should be seen then as an investment in the cultural future of all Australians.

Indigenous media producers who participated in the 1998 Digital Dreaming review of the sector were adamant of the need to move towards self-sufficiency. It was a powerful unifying element of the study remarked on by all members of the review team at the time. This suggests the need to pursue strategies which make Indigenous media 'ordinary' rather than 'extraordinary' or 'unique' - in other words, to enable Indigenous people to access media on the same equal basis as non-Indigenous Australians. This is a crucial point needed to counter claims that Indigenous people somehow receive 'special treatment', suggesting they get more than other Australians - rhetoric which continues to re-surface within the framework of conservatism currently gripping Australian politics. And so the 'exceptional' strategies required should be seen as ones which create 'sameness' rather than uniqueness (Mickler 1998, 292).

The complexities of Indigenous communications have been highlighted by Morris who reminds us that Indigenous media producers must become involved in debates 
associated with intellectual property because of the potential impact of technological convergence, globalism of content, and the lack of protocols and regulations applying to the ever-increasing number of on-line and multimedia services (UNESCO 1995, 107; Meadows and Morris 1998, 3, 11). These are critical questions that Indigenous communication industry workers are confronting now.

This might suggest conflict between notions of the highly controlled information flow in traditional Indigenous societies versus western notions of editorial independence and the public's right to know-implicit in much of the rhetoric around new information technologies. O’Regan suggests (1990, p.61) that journalism routines, for example, encourage violations. Indigenous media producers are confronting similar difficulties in coming to terms with the western notion of copyright and how this might interact with Aboriginal concepts of ownership of cultural products.

While some have argued against the idea of a national Indigenous broadcasting service because of the importance of local social organisation and the problem of incorporating the many Indigenous languages spoken across the continent (Michaels 1986), others challenge this. They suggest that the structure of Indigenous languages is such that they do not represent 'incommensurable universes' but are often closely related with many common grammatical and sound features - in other words, they have 'very leaky boundaries' (Hodge 1990). At least 12 communities in the Tanami Desert, for example, have linguistic similarities which might enable them to be linked by a network using, for example, one language as a lingua franca.

In the light of this, the Indigenous communications sector has begun a push in earnest for centralising the management and organisation of Indigenous media through a statutory body called Indigenous Communications Australia (ICA). The Digital Dreaming review report identified this entity as an Indigenous Media Authority (1999, 66-67). This idea is central to the development of a National Indigenous Broadcasting Service (NIBS) which incorporates both radio and television broadcasting. The efficiencies which flow from other models of national broadcasting like the ABC and SBS suggest that a well-planned and managed Indigenous broadcasting service, adequately funded, would deliver a substantial and ongoing public benefit (Applied Economics 1999).

The idea of moving towards a National Indigenous Broadcasting Service dominates the submissions made to the Productivity Commission inquiry by both the National Indigenous Media Association of Australia (NIMAA) and ATSIC. The timing of the ATSIC submission, in particular, meant that the commission was unable to respond to this suggestion in its draft report although it has indicated the issue will be addressed in the final report (Productivity Commission 1999, 99).

This article reviews these submissions and the commission's recommendations within the context of the historical development of the Indigenous media policy environment in Australia. 


\section{The Satellite Program Services inquiry}

One of the earliest attempts to formulate an Indigenous media policy was in 1980 when Department of Aboriginal Affairs personnel formed a media working party with representatives of the then Posts and Telecommunications Department. But it was not until the 1984 Satellite Program Services (SPS) inquiry by the Australian broadcasting Tribunal into use of Australia's then proposed domestic communications satellite, AUSSAT, that Indigenous broadcasting concerns were first raised during public hearings. The federal government accepted the SPS's recommendations and subsequently licensed three Remote Commercial Television Services-Golden West Network (WA), Imparja (NT) and QTV (QLD).

Around the same time, AUSSAT conducted its own investigation into Indigenous fears, perceptions, and expectations of satellite communication. The report recommended that AUSSAT provide support for the evolution of independent Aboriginal and Torres Strait Islander production centres and suggested that particular attention be given to the design and development of the second generation of AUSSAT satellites due in 1993 to facilitate Indigenous production (Walsh Vol. 1 1984, p.17). AUSSAT, like all other agencies involved, ignored the recommendations. Sixteen years later, they offer a prescient critique of the current technological and policy environment which sees Indigenous media producers still trying to negotiate basic access agreements to television, for example.

\section{Out of the Silent Land}

At the same time as the SPS inquiry was underway in 1984, a federal government task force prepared a report into Aboriginal and Torres Strait Islander broadcasting-Out of the Silent Land. It was the first attempt to develop a coherent policy on Indigenous broadcasting in Australia and was largely in response to Indigenous fears over the possible impact of satellite television, particularly in remote Australia. The report made 55 recommendations and included the following, of particular significance to remote communities:

- the coordinated introduction of satellite radio and television reception and rebroadcasting facilities to remote Aboriginal and Torres Strait Islander communities;

- the provision of facilities to allow Aboriginal and Torres Strait Islander people to control programs broadcast in their communities; and

- the encouragement of Aboriginal and Torres Strait Islander broadcasting in radio and television production (Willmot 1984, vi-xiii).

All of the recommendations were accepted by the federal government in an environment where the imminent broadcasting of English language satellite television into remote Indigenous communities was being described as 'cultural nerve gas' (Fesl 1985). These fears closely parallel those of the Inuit who described southern television broadcasting to the northern Native peoples of Canada, 12 years earlier, as 'neutron bomb television' (Kuptana 1987).

The key issue of funding was all but ignored in the report, leaving the responsibility entirely with the then Department of Aboriginal Affairs (Willmot 1984, vi-xiii). The 
task force identified a failure by commercial broadcasters to contribute to Aboriginal broadcasting and it placed an onus on $\mathrm{ABC}$ and commercial stations in remote areas to cater for Aboriginal concerns (Willmot 1984, p.127). It recommended that licensing provisions for remote area commercial services should recognise the special interests of the remote Aboriginal population (Willmot 1984, p.142). This was subsequently adopted during licence hearings for all Remote Commercial Television Services but the strategy had minimal impact on programming, largely because of a lack of willingness to participate and the cost of local production (Molnar and Meadows forthcoming).

One positive outcome of Out of the Silent Land was the Broadcasting for Remote Aboriginal Communities Scheme (BRACS). From 1987, around 80 Indigenous communities were identified and provided with rudimentary radio and television receiving equipment along with the potential for minimal local radio and video production. The number of BRACS' communities is currently around 130 . The scheme has had mixed success because of a lack of consultation and a lack of funding for training, program production, and maintenance. The original idea of BRACS did hold out some hope for local control and thus diversity across the country. Critically, there was no attempt to enshrine the concept of BRACS in community social structures - a fundamental flaw which meant the chance of success would be low (Molnar and Meadows forthcoming). Katz (1977) has suggested that 'radical suggestions' are needed for making media more relevant to traditional societies and in general, BRACS has failed to do this. But there are notable exceptions-a trend towards grouping BRACS communities into regional enclaves has had some success in the Kimberleys, the Top End, Cape York and central Australia.

\section{Satellite debates}

The first two AUSSAT satellites were launched in 1985 amidst claims that they would provide and maintain air navigation facilities, extend ABC broadcasting services to remote communities, and provide telephone and emergency services to remote areas (Gray et al 1987). Australia had been using the International Telecommunications Satellite Organisation satellite (INTELSAT), along with 13 other countries, since 1964. The lead-up to the launch of the first AUSSAT satellite saw a prolonged debate which provoked Out of the Silent Land. Much of the concern around the impact of AUSSAT centred on the threat to Aboriginal languages and culture.

By the end of 1992, satellite television had gained a foothold across mainland Australia and in all Torres Strait Island communities where BRACS was operating. In the Torres Strait, BRACS was being used as a means of watching mainstream commercial television. This remains largely unchanged in 2000. A 1992 study in the Torres Strait revealed that concerns about the impact of television varied across the islands. On Murray Island, where the number of speakers of the local language, Meriam, is in decline, there was grave concern over the influence of English-language television on linguistic and cultural maintenance. But on Boigu Island-just six kilometres from Papua New Guinea-the community there expressed no such fears. Their perception was that 'the culture and language are strong', despite the arrival of television. This is perhaps explained in that Kala Lagaw Ya or 'Top Western'-the first language of Boigu Islanders - has more speakers than any of the 90 remaining 
'living' Indigenous languages in Australia (House of Representatives Standing Committee 1992, pp.24-25). Nevertheless, it was clear from these community responses that television had positioned itself as part of the lifestyle of Torres Strait Island people soon after it was available (Meadows 1995).

\section{The ATSIC Indigenous media policy}

Despite the existence of the report, Out of the Silent Land, there were no serious attempts to develop a workable Indigenous media policy within the Department of Aboriginal Affairs until 1989. In the next few years, several drafts resulted from negotiations between the newly-formed Aboriginal and Torres Strait Islander Commission (ATSIC) and the Department of Transport and Communication. In 1991, the joint discussion paper was released for comment. It acknowledged recommendations of the Royal Commission into Aboriginal Deaths in Custody, which urged adequate funding for Aboriginal-controlled media in recognition of its social function. A similar view was expressed in the Human Rights and Equal Opportunity Commission Report of the National Inquiry into Racist Violence, handed down in the same year. The discussion paper suggested using possible technical developments such as cable delivery, CD quality sound from digital audio broadcasting, and compression techniques to allow for more creative use of existing facilities.

Between 1982-85, the National Aboriginal and Islander Broadcasting Association (NAIBA) existed to represent the needs of Indigenous broadcasters in the policy process. Following a seven year gap, the National Indigenous Media Association of Australia (NIMAA) emerged to replace NAIBA as a key lobbying and policy unit in December 1992. NIMAA has a membership of around 130 community media producers across all sectors - print, radio, television and video, multimedia, and film.

In January 1993, a draft policy statement was circulated to Indigenous broadcasters for comment and input and shortly after, was adopted as ATSIC's first Indigenous broadcasting policy. It was justified in these terms:

- Equity considerations: Indigenous people should have the right to full access to information and entertainment available through national and regional media.

- Cultural restoration, preservation and growth: Broadcasting has the potential to provide communities with means to maintain languages and cultures.

- Efficiency of communication: Indigenous access and/or control of local radio and television can substantially improve delivery and exchange of vital information on such issues as health, child welfare, substance abuse, domestic violence, education etc.

- Employment: Indigenous control provides employment and training opportunities in urban and remote communities and the possibility of access to mainstream media employment.

- Enhanced self-image: Watching or listening to culturally and linguistically relevant programming enhances a sense of worth and community profiles.

These key concepts remain at the core of the Indigenous media policy process and resurfaced in ATSIC's submissions to the Productivity Commission. 


\section{Digital Dreaming}

In 1998, ATSIC commissioned another review of the Indigenous media sector-a follow-up to Out of the Silent Land. Called Digital Dreaming, it was the most comprehensive study yet undertaken of all aspects of the expanding and diverse sector. It involved extensive consultations with Indigenous people and organisational representatives in community radio, print, multimedia, video and film production. The 500 page report made 131 recommendations, including the establishment of a dedicated Indigenous broadcasting program production fund. ATSIC accepted all of the recommendations and subsequently published an edited version of the report in 1999. The review team identified a number of key issues:

- that Indigenous media provided their communities with a first level of service;

- that in view of the unique service Indigenous media offer their audiences, the federal government view continued funding of Indigenous media as an investment to enable planning for the industry's long-term sustainability;

- the need for relevant funding agencies—specifically, ATSIC, DETYA and DoCITA - to adopt a 'whole of organisation' approach in coordinating their activities in relation to the Indigenous media sector;

- the need for all Indigenous media organisations to develop their own business and marketing plans;

- that in view of the convergence of content production, delivery systems, and service providers, ATSIC needs to develop integrated strategies for making the best use of this technological environment;

- the need for federal government departments to be aware of the extent and nature of the Indigenous media sector and to use it as a unique service provider;

- that federal government departments use the extraordinarily diverse range of commercial services offered by the Indigenous media sector; and

- that the widely-expressed desire by Indigenous media workers for economic independence will not be possible in some locations. Some government assistance will always be necessary in view of the cultural and economic benefits generated by industry sectors.

Since the completion of the review, ATSIC and NIMAA have been engaged in a process of identifying priority areas and in setting up a 5-10 year plan for implementation of the many recommendations. The Productivity Commission's inquiry into broadcasting is the latest public investigation to tap into this policy process.

\section{Inquiry submissions}

A handful of the 177 submissions to the inquiry specifically dealt with the issue of Indigenous communications. As expected, Digital Dreaming with its 131 recommendations was influential in framing these. Three key organisations made submissions to the inquiry in relation to Indigenous media policy-ATSIC, NIMAA and the West Australian Aboriginal Media Association (WAAMA). 


\section{WAAMA}

The WAAMA submission, in March 1999, argued that Indigenous media was 'an essential service to everyone...specifically in areas of community development, race relations, land administration and environmental matters'. It stressed the crucial role Indigenous media played in the path to reconciliation (WAAMA 1999a). In a followup submission in June, the organisation put forward two recommendations:

- that a levy on commercial sector media operations be imposed to fund the Indigenous sector (1999b, 2-3); and

- that the ABA oversee an accord between the commercial and Indigenous media sectors for training of Indigenous media workers, similar to the arrangement which operates in the USA concerning the training and employment of African Americans in the entertainment industry (WAAMA 1999b, 5).

The commission did not address either of these issues in the draft report, arguing that funding was beyond the inquiry brief (Productivity Commission 1999, 100).

\section{NIMAA}

The National Indigenous Association of Australia (NIMAA) made three submissions as well as giving oral testimony at the commission's public hearings. NIMAA put forward strong views that argued the Indigenous media sector was the only distinct broadcasting group that 'cost-effectively, culturally and linguistically provides essential service information to Indigenous Australians'. The submission underlined the continuing need for government funding and the importance of maintaining 'access and equity for Indigenous Australians' to appropriate media technologies to enable maintenance of Indigenous languages and cultures. Importantly, the submission acknowledged the role of the sector in fostering reconciliation (NIMAA 1999a, 2).

A further submission by the NIMAA executive and its National BRACS Working Party in August took the debate a step further by recommending the setting up of a statutory authority, Indigenous Communications Australia (ICA), to oversee management and operation of the sector. The submission argued that NIMAA and/or ICA could:

- ensure that Indigenous organisations were given adequate notice of technological changes and their processes of implementation (e.g. shift from analogue to digital television); and

- give advice regarding community boundaries in remote areas to ensure that communities were not divided along state, territory or other artificial boundaries (NIMAA 1999b).

The key point of the submissions was to reinforce the feeling across the sector of a need for self-determination through the establishment of Indigenous Communications Australia aimed at 'uniting all Indigenous media'. Similar moves have been mooted in Canada but at the time of writing, no representative body had emerged (First Nations Management and Associates 1998). The Australian version of the concept was likened to setting up a national communications service similar to those operated by the ABC and SBS. The submission argued (1999c, 8): 'We want the opportunity 
to tell our own stories in our own languages... and to write, film, edit, produce and broadcast our own stories about issues of importance to Australia and the world.' NIMAA described the Indigenous media sector in these terms (NIMAA 1999c, 6):

- over 100 permanently licensed community television and radio stations;

- 40 broadcasting groups aspiring for permanent community radio licenses;

- one commercial television station-Imparja Television, Alice Springs;

- one commercial radio station-Yamitji Media, Carnarvon, WA;

- over 50 film, video and multimedia producers; and

- one national and various regional and local newspapers.

The NIMAA submission alluded to the possible of leasing one of four digital TV channels to enable Indigenous television to be received wherever ABC TV was broadcast. The submission argued that such an arrangement would require 'no extra infrastructure' for enabling transmission of an Indigenous television network (NIMAA 1999c, 14).

\section{ATSIC}

The issue of Indigenous Communications Australia (ICA) was taken up by ATSIC in its two submissions and one response to the inquiry. From the outset, ATSIC reaffirmed its policy objectives as follows (1999a, 22):

- to enable Aboriginal and Torres Strait Islander peoples access, particularly in remote areas, to receive the range of broadcasting and communications services available to Australian citizens generally; and

- to develop and extend Aboriginal and Torres Strait Islander broadcasting and communications to reinforce and promote the cultural identities of Aboriginal and Torres Strait Islander peoples and to foster awareness of their cultures.

In arguing for the recognition of - and appropriate funding for-Indigenous broadcasting as a sector in its own right, ATSIC asserted that the planning, licensing and regulatory processes should be directed towards creating an Indigenous broadcasting sector with twin aims:

- $\quad$ to provide Indigenous Australians with primary broadcasting services; and

- to inform mainstream Australia about our Indigenous peoples and their cultures.

This approach clearly picks up on the dual function of Indigenous media identified in Digital Dreaming $(1999,5)$. While acknowledging the limited scope of the inquiry, ATSIC nevertheless presented an outline for the establishment of a national Indigenous broadcasting service. It put forward three recommendations as 'essential precursors' for such a service (1999b, 14, 34):

- that the Objectives of the Broadcasting Services Act 1992 should be amended to recognise the special role of Indigenous broadcasting (like Canada and NZ); 
- that ministers should commission a feasibility study to report on possible migratory paths to an Indigenous broadcasting authority (now called Indigenous Communications Australia, ICA);

- that BRACS licences should be substantially modified;

- that the government begins a round of negotiations with existing Indigenous broadcasters regarding their relationship with the proposed ICA;

- that government support for an interim ICA be established; and

- that by 1 January 2003, national ICA radio and television networks be established.

The basis of the ATSIC submissions was that Australia is - and should be-an egalitarian society where citizens enjoy freedom of expression as a right. And it continued (1999b, 14):

Since our broadcasting system is one of the electronic highways along which modern societies communicate, access to it should be rights based. Citizens denied access to broadcasting are denied their birthright. The success of Australia's unique experiment in ethnic broadcasting demonstrates that the broadcasting system can be a powerful instrument for communicating with specific communities as well as developing mutual understanding. Australia's 386000 Indigenous Australians have an even more pressing need for special services than our migrant communities, yet the services provided for them remain inadequate. Many Indigenous people speak English only as a second, third or fourth language. Loss of their own Languages exacerbates their cultural dislocation.

The submission argued that a national Indigenous broadcasting service, through the ICA, would provide 'significant training' for mainstream employment. It would alert Indigenous communities to the services available to them. It would provide opportunities for increasing trade with the outside world. And it would improve Indigenous peoples' confidence as well as enhance their standing in the general community:

We believe that establishment of the ICA would make an important contribution to the process of Reconciliation. It would be standing testimony to Australia's respect for its Indigenous peoples, their art and their cultures and would be recognised as such both here and abroad (ATSIC 1999b, 11).

The ATSIC submission argued that an Indigenous broadcasting service should be seen as providing a 'primary service' to Indigenous peoples as well as offering 'a true cultural and economic bridge across which all Australians may travel towards Reconciliation' (ATSIC 1999b, 14). The arguments put forward here are remarkably similar to many of those suggested in the AUSSAT investigation 15 years earlier (Walsh 1984). ATSIC voiced support for the NIMAA-initiated ICA and without favouring any, suggested the three 'most feasible' options for its implementation (1999b, 11):

- Option A: as an independent national broadcaster;

- Option B: as a division within an existing national broadcaster; and 
- Option C: as a community broadcaster.

In a response to questions raised by the Productivity Commission following its public hearings in Brisbane, ATSIC emphasised that an Indigenous broadcasting service already existed and that the aim of the exercise was to consolidate this. It argued that a National Indigenous broadcasting Service (NIBS) would perform two complementary but distinct functions $(2000,2)$ :

- to provide a primary (first level) broadcasting service to Indigenous Australians; and

- to inform mainstream Australians about our Indigenous peoples and their cultures.

ATSIC argues with good reason that radio should be given first priority because of the extensive infrastructure and production networks already in place $(2000,5)$. However, the ATSIC submission warns against 'bundling' an Indigenous broadcasting service with the multicultural broadcaster, SBS (2000, 6). This stems from a strongly-held view amongst Indigenous people of their distinctiveness in terms of the broad tag of 'multiculturalism'.

Drawing from studies in Australia, Canada, and New Zealand, the submission highlighted strong Indigenous audience preference for Indigenous material when it is available. A 1997 survey of urban audiences for Brisbane community radio station 4AAA revealed that the station had not only reached a substantial portion of Brisbane's Indigenous community, but also was perceived (along with newspapers) as the most important information source about Indigenous affairs-after word of mouth. Mainstream television and radio were ranked near the bottom of a list of sources of Indigenous information (Meadows and van Vuuren 1998).

Audience surveys in the early 1990s for the Aboriginal television network, Television Northern Canada (TVNC), revealed a large Indigenous audience across Canada's remote north with up to 86 percent watching 'some' of its programs (Wilson 1993a; Wilson 1993b). In 1998, before TVNC transformed into the Aboriginal People's Television Network (APTN), market research in southern Canada revealed 87 percent of Native people questioned said they would either 'definitely watch' or 'probably watch' the Aboriginal television channel (APTN 1998; David 1998, 39).

Similarly, research into viewing audiences for a 1996 pilot broadcast for the new national Maori Television channel, revealed around half the Maori population of Auckland were viewers (Te Mangai Paho 1996, 21). This strong audience response confirmed the importance and popularity of Maori television and was significant in encouraging the development and launch of the national Maori television service late in 1999. The submission concluded there was mounting audience research data to support anecdotal evidence of audience support-both Indigenous and nonIndigenous - for Indigenous radio and television programming in remote, regional and urban settings (ATSIC 2000, 7-9).

\section{Productivity Commission recommendations}

The commission's draft report included four recommendations pertaining to the Indigenous media sector. Two, in Section four of the draft report, albeit pertaining to licensing and spectrum management issues, acknowledge the separation of the 
Indigenous media sector from the community sector - a fundamental issue raised in Digital Dreaming (1999, 16):

\section{Draft Recommendation 4.5}

The ACA should estimate and report publicly on the value of broadcasting services bands spectrum reserved for national, community and Indigenous broadcasting services (Productivity Commission, 1999, p. 80).

\section{Draft Recommendation 4.6}

Simplified processes for reserving sufficient spectrum for national, community and Indigenous broadcasters should be adopted. All unreserved broadcasting spectrum should be made available for commercial broadcasting uses (Productivity Commission, 1999, p. 80).

This acknowledgment of the 'unique role' of Indigenous media in Australia is a significant move from past thinking on policymaking which has tended to view Indigenous media production as synonymous with community broadcasting. This approach led the commission to consider two further recommendations more specifically directed to the Indigenous media sector. The commission's rationale is expressed as follows:

Indigenous radio and television help to sustain language and culture; they provide a vital channel of news and information for Indigenous people; and they have the potential to provide a means for better communication between Indigenous and other Australians (Productivity Commission 1999, XLIII).

The draft report argues that Indigenous radio and television services are 'not well served by the community broadcasting licence category which is now used to regulate the sector. The objectives and management of Indigenous media are very different from those of community broadcasters'. In adopting this stance, the commission recommends that a new licence category for Indigenous broadcasters be established 'to foster the development of this important broadcasting service and that, where appropriate, spectrum should be reserved for this purpose' (1999, XLIV). The first of these recommendations addresses the need for a special licence category:

\section{Draft Recommendation 5.2}

A new licence category for Indigenous broadcasters should be created, with appropriate conditions relating to advertising (Productivity Commission, 1999, p. 104).

The second recommendation addresses the need for spectrum allocation:

\section{Draft Recommendation 5.3}

Spectrum should be reserved for Indigenous broadcasters that provide a primary level of service to a specific audience, in accordance with the licence allocation process recommended in chapter 4 (Productivity Commission, 1999, p. 104).

The Productivity Commission has acknowledged that the primary objective of the Indigenous media sector is to provide a 'first level of service' for Indigenous people-a media service for Indigenous communities specifically, often in the absence of any other broadcasting (Productivity Commission 1999, 100): 
- First, Indigenous media seek to provide information and locally made programs which are in Indigenous languages and relevant to Indigenous communities. Such programs include news, children's programming, documentaries and sport coverage.

- Second, Indigenous media aim to disseminate public service information to Indigenous communities on subjects such as law, health, housing and education.

Reflecting the key recommendations of the Digital Dreaming report, the commission acknowledges that Indigenous media 'have the potential' to serve both relatively large Indigenous populations and non-Indigenous audiences. This suggests Indigenous media are involved in other important social, cultural and economic objectives within the Australian broadcasting environment (Productivity Commission 1999, 101):

- to offer a 'cultural bridge' between Indigenous and non-Indigenous Australians. Despite limited research on the subject, audience studies suggest that some Indigenous media services have significant non-Indigenous audiences, and may play an important cross-cultural role in furthering reconciliation; and

- to offer skilled work opportunities and the potential to reduce the economic dependence of Indigenous communities on governments, in remote and regional Australia and in urban centres.

The question of the possibility of using either ABC or SBS broadcasting infrastructure to deliver a National Indigenous broadcasting Service is not conclusively addressed in the draft report. This question, of course, will need to be resolved through negotiations between representatives of the Indigenous media sector and the national and multicultural broadcasters.

\section{Conclusion}

For the first time, a major review of Australian broadcasting policy has looked seriously at the Indigenous media sector and has recognised its achievements along with its potential. This is clear from the way in which the commission's draft report has addressed aspects of Australian broadcasting which includes the Indigenous media sector, rather than seeing it as something operating on the periphery. The commission's analysis of the sector has carefully considered a wide range of opinion in formulating its draft recommendations. This included the comprehensive Digital Dreaming review and numerous submissions_-both written and verbal-from ATSIC and representatives of the Indigenous media sector itself. The only background paper commissioned for the inquiry dealt with Indigenous media (Productivity Commission 1999, Appendix C). This is indicative of a sensitive approach to Australia's fastestgrowing media sector and represents a significant shift in thinking at a crucial level in the national policymaking process.

While technological determinism continues to play a significant role in shaping the Indigenous media policy and production environment in Australia, the response by the Productivity Commission suggests that policymakers are beginning to recognise the importance of Indigenous agency. In the early 1980s in the lead up to the launch 
of the domestic satellite, AUSSAT, debates centred on deep suspicion of the impact of English language television on surviving Indigenous languages and cultures. The arrival of video cassettes in remote Indigenous communities and the imminent launch of the satellite fuelled these fears. This conflict between western concepts of the free availability of information and traditional forms of information management were hastily addressed in the 1984 task force report, Out of the Silent Land-which became the basis for policy development - and were raised in the same year during the Satellite Program Services inquiry conducted by the Australian Broadcasting Tribunal. While there was acknowledgment of the possible impact of Western television programming on the languages and cultures of remote Indigenous communities, the silence from policymakers on the role of Indigenous media in this process was deafening. While BRACS was one product of the debate, it was viewed primarily as a 'quick fix' rather than a long-term strategy to enable Indigenous communities to have some control of their communication futures. Despite this, many communities have been able to appropriate BRACS to suit their cultural needs.

There is a growing body of research that suggests that significant remote, rural and urban Indigenous audiences see their own media as offering a first level of service in providing information of particular interest to them. Indigenous media most often provide the only source of information — apart from word of mouth—about local Indigenous affairs and in this sense play a crucial supplementary role to mainstream media which aim to attract a more general audience. The research from Australia, Canada, and New Zealand, coupled with overwhelming anecdotal evidence from other Indigenous broadcasters, suggests that Indigenous media, built on a strong local or regional community base, is attracting - and will continue to attract-significant Indigenous audiences in remote, rural, and urban areas.

The 1993 ATSIC Indigenous media policy was justified in terms of the need for equity, cultural restoration and growth, efficiency of communication, employment, and an enhanced self image. However, funding remains uncertain and ad hoc, tied to the Aboriginal and Torres Strait Islander Commission. Moves to establish Indigenous Communications Australia seek to shift this responsibility to Indigenous people. The crucial question of funding remains unanswered.

A successful Indigenous communication model will have to take into account broader questions of how media production can be appropriately incorporated into community social structures. It will need to address the question of how Indigenous and nonIndigenous law might co-exist, for example. Morris has argued that this may not be as problematic as some would suggest, provided 'proper protocols' are instituted. This means acknowledging the central place of protocols against the constraints of finance and time, for example. More often than not, protocols are relegated to the category of 'the ideal' when things have to be done according to criteria influenced by non-Indigenous law and commerce (Morris 1998, 13; forthcoming).

The draft recommendations of the Productivity Commission considered here represent a significant step forward in the policymaking process. They begin, at least, to acknowledge the important relationship between Indigenous cultural production and the social structures from which this emerges. Two specific recommendations (5.2 and 5.3) are evidence of this. But this should be seen as just a step when viewed against the broader questions of cultural protocols which should be at the heart of any Indigenous broadcasting system. The 131 recommendations of the 1998 Digital Dreaming review offer some help here. 
Another suggestion which could make administering Indigenous radio much less complex would be to abandon the idea of the need for a licence for remote radio altogether. The Canadian Radio-television and Telecommunications Commission (CRTC) — Canada's equivalent of the Australian Broadcasting Authority—in 1998 did just this. Aboriginal radio stations operating in remote areas with no commercial competition no longer need to seek a licence-they simply start broadcasting. The CRTC argues that this exemption is the 'most efficient way to ensure that the broadcasting undertakings falling within the exempted cases are able to devote the maximum amount of their limited resources to the provision of service, rather than to the fulfilment of administrative concerns'. New Native radio stations in remote areas now need complete a one page registration form. Stations with an exempt status are not required to keep broadcasting logs nor are subject to Canadian content requirements (CRTC 1998, 1-2). Is there a good reason why such a system would not work in remote Australia?

Another area of critical symbolic importance not addressed in the Productivity Commission's draft report is the need to amend the Broadcasting Services Act to acknowledge the special place of Indigenous languages and cultures. As the inquiry's only commissioned paper explains, both Canada and New Zealand have included such an acknowledgment in relevant legislation since the early 1990s (Productivity Commission 1999, C1-C18). The commission's draft report deals with this in terms of the structural diversity of the Broadcasting Services Act and does not acknowledge deficiencies. But what must be remembered here is that providing Indigenous media with its own licence category is just the first step-as the commission itself acknowledges, Indigenous media perform a dual function in providing a 'cultural bridge', filling the information gaps left by mainstream media. The real onus should be on mainstream sectors to address these shortcomings and an appropriate amendment acknowledging the special place of Indigenous languages and cultures might go some way to impressing on broadcasters their obligations in this regard.

Digital Dreaming made this same recommendation and it is disappointing not to find it taken up here.

So despite a significant move forward, policymakers and government legislators still have some challenging times ahead if they wish to lay claim to being cognizant of the needs of Australia's burgeoning Indigenous communications industry and the multiple roles it performs now, or has the potential to perform. Producing appropriate draft recommendations is an achievement in itself-but converting them into appropriate action is another thing entirely.

\section{References}

Applied Economics, 1999, Report on National Public Broadcasting Benefit, background paper.

APTN, 1998, Seeing Canada through Aboriginal eyes: licence application, Aboriginal Peoples Television Network, Ottawa, 5 June. 
ATSIC, 1999a, Indigenous Communications Australia (ICA): A proposal to meet the broadcasting needs of Australia's Indigenous peoples, Submission to the Productivity Commission by the Aboriginal and Torres Strait Islander Commission (ATSIC), September.

ATSIC, 1999b, Rationale for an Indigenous broadcasting Service, Submission to the Productivity Commission by the Aboriginal and Torres Strait Islander Commission, November.

ATSIC, 2000, Answers to questions raised by the Productivity Commission, Brisbane 17 December regarding the Indigenous broadcasting Service (IBS), Prepared for the Aboriginal and Torres Strait Islander Commission (ATSIC), January.

Canadian Radio-television and Telecommunications Commission, 1998, Exemption order respecting certain native radio undertakings, 9 July, Ottawa.

David, Jennifer, 1998, 'Seeing ourselves, being ourselves', Cultural Survival Quarterly, vol. 22, Issue. 2, pp. 36-39.

Fesl, Eve, 1985, Aborigines and Language, paper presented to ANZAAS Festival of Science, Monash University, August, pp. 1-25.

First Nationa Management \& Associates, 1998, Aboriginal broadcast Entity: Corporate Strusture Options, Prepared on behalf of the Aboriginal broadcasters Working Group, Ottawa, March.

Gray, Leo; Robert Orr; and Lesley Hitchens, 1987, Communications Law and Policy in Australia, Sydney, Butterworths, pp. 3801-3803.

Hodge, Robert, 1990, 'Aboriginal Truth and White Media: Eric Michaels meets the Spirit of Aboriginalism’, Continuum, vol. 3, no. 2, pp. 201-225.

House of Representatives Standing Committee on Aboriginal and Torres Strait Islander Affairs, 1992, A Matter of Survival: Report of the Inquiry into Aboriginal and Torres Strait Islander Language Maintenance, June, Canberra, Australian Government Publishing Service.

Katz, Elihu, 1977, 'Can Authentic Cultures Survive New Media?’, Journal of Communication, Spring, pp. 113-121.

Kuptana, Rosemarie, 1987, 'In the land of midnight television', in Retrospective:

Twenty Years of Aboriginal Communications in Canada, National Aboriginal Communications Society.

Meadows, Michael, 1995, 'Voice blo mipla all ilan man: Torres Strait Islanders' struggle for television rights', in (eds.) J. Craik, J. James-Bailey, and A. Moran, Public Voices, Private Interests: Australia's Media, Sydney: Allen and Unwin, pp. 179-198.

Meadows, Michael and Christine Morris, 1998, 'Into the new millennium: the role of Indigenous media in Australia', Media International Australia, no. 88, pp. 67-78.

Meadows, Michael and Kitty van Vuuren, 1998, 'Seeking an audience: Indigenous people, the media and cultural resource management' Southern Review, vol. 31, no. 1, pp. 96-107.

Michaels, Eric, 1983, ‘Aboriginal Air Rights’, Media Information Australia, no. 34, pp. 51-61. 
Michaels, Eric, 1986, Aboriginal Invention of Television Central Australia 19821985, Canberra, Australian Institute of Aboriginal Studies.

Mickler, S. 1998, The myth of privilege: Aboriginal Status, Media Visions, Public Ideas, Fremantle Arts Centre Press, Fremantle.

Molnar, Helen and Meadows, Michael, forthcoming, Songlines to Satellites:

Indigenous communication in Australia, the South Pacific, and Canada, Pluto Press, Sydney.

Morris, Christine, 1998, 'Cultural considerations report', Into the New Millennium: Indigenous media in Australia project, Australian Key Centre for Cultural and Media Policy, background paper.

Morris, Christine, forthcoming, 'Constitutional dreaming', (eds.) Charles Sampford and Tom Round, Beyond the Repoublic: Meeting the global challenges in constitutionalism, Proceedings of the 1999 Fulbright Symposium.

NIMAA, 1999a, The Indigenous Communications Sector: An Essential Service Provider, Submission to the Productivity Commission inquiry into broadcasting, May.

NIMAA, 1999b, Remote area satellite conversion process from analogue to digital, Submission to the Productivity Commission inquiry into broadcasting, August.

NIMAA, 1999c, From message stick to multi-media in the new millennium: Indigenous Communications Australia, Submission to the Productivity Commission inquiry into broadcasting, September.

O’Regan, Tom, 1990, 'TV as Cultural Technology: The Work of Eric Michaels', Continuum, vol 3, no 2, pp. 53-98.

Productivity Commission, 1999, Broadcasting: draft report, Ausinfo, Canberra.

Te Mangai Paho, 1996, Post Election Brief, Wellington, December.

Thomas C. Wilson, 1993a, Satellite Television in the Canadian Arctic 1974-1992:

Cultural Replacement and Regeneration, Paper presented at the Post Colonial Formations Conference, Griffith University, Brisbane, July 14-17.

Thomas C. Wilson, 1993b, Some Demographic Characteristics of the Population of Northern Canada, Paper prepared for Television Northern Canada, 31 August.

UNESCO 1995, Our Creative Diversity: Report of the World Commission on Culture and Development, World Commission on Culture and Development, Paris.

WAAMA, 1999a, Broadcasting Issues Paper, WAAMA, March.

WAAMA, 1999b, Australian Broadcasting Act Inquiry 1999, WAAMA, June.

Walsh, Brian and Associates, 1984, Aboriginal Use of AUSSAT: A Feasibility Study for AUSSAT Pty Ltd, vols. 1\&2, Submission, Australian Broadcasting Tribunal records.

Willmot, Eric, 1984, Out of the Silent Land, Canberra, Australian Government Publishing Service. 


\section{Indigenous media policy development: some highlights}

- 1980: The Central Australian Aboriginal Media Association (CAAMA) lobbies for Aboriginal media access and input to policy formation.

- 1980: A Department of Aboriginal Affairs working party looks at Indigenous media policy options.

- 1983: Warlpiri Media Association’s first ‘pirate’ TV test transmission 1 April.

- 1982-85: National Aboriginal and Islander Broadcasting Association (NAIBA) represents lobbying efforts of Indigenous broadcasters.

- 1983: Canada’s Northern Native Broadcast Access Program is established.

- 1984: The Satellite Program Services inquiry hears Aboriginal concerns about mainstream programming.

- 1984: Out of the Silent Land report is released.

- 1985-86: The Remote Commercial Television Service inquiries take account of Indigenous concerns over programming and set conditions on licences.

- 1987: BRACS units begin to be installed in remote Indigenous communities.

- 1988: The remote commercial station Imparja Television begins broadcasting.

- 1989: First attempts by DAA to develop an Indigenous media policy.

- 1990: Canada issues an Aboriginal Broadcasting Policy.

- 1991: ATSIC-DOTAC broadcasting policy paper released for discussion.

- 1991: The report of the Royal Commission into Aboriginal Deaths in Custody recommends federal government support for Indigenous media initiatives.

- 1991: The report of the Human Rights and Equal Opportunity Commission's Racist Violence Inquiry recommends support for Indigenous media.

- 1992: Television Northern Canada (TVNC) begins broadcasting.

- 1992: The National Indigenous Media Association of Australia (NIMAA), representing all Indigenous broadcasters is formed.

- 1993: The ATSIC Indigenous broadcasting policy is adopted.

- 1996: The National Indigenous Radio Service is launched on 25 January.

- 1998: The Digital Dreaming review of Indigenous media.

- 1999: The Productivity Commission inquiry into broadcasting.

- 1999: A national Maori television channel in New Zealand is launched.

- 1999: TVNC is extended into southern Canada via cable.

- 2000: ATSIC undertakes a feasibility study for development of a National Indigenous Broadcasting Service (radio and television) by 2005. 